\title{
DESENVOLVIMENTO DA IMAGINAÇÃO DE CRIANÇAS COM TRANSTORNO DO ESPECTRO DO AUTISMO (TEA) NA PERSPECTIVA HISTÓRICO-CULTURAL
}

Daniele Souza Peres, Janaína Pereira Duarte Bezerra, Rafael Cesar Ferrari dos Santos.

Universidade do Oeste Paulista - UNOESTE, Curso de Educação Física, Presidente Prudente, SP. E-mail: dsphp peres@hotmail.com

\section{RESUMO}

O desenvolvimento da função psicológica superior imaginação da criança com Transtorno de Espectro Autista (TEA) é descrito como muito restrito e peculiar. Com a preocupação pela busca de práticas educativas promissoras, o presente artigo tomou como referência a Teoria histórico-cultural e teve o objetivo de evidenciar a particularidade do desenvolvimento da imaginação da criança com TEA visando compreende-la. O levantamento bibliográfico nos possibilitou compreender que as crianças autistas podem apresentar ações imaginativas desde que aconteça um desprendimento da situação imediato-concreta, pela qual a significação passa a subordinar a percepção que é típica do processo de imaginação. Trata-se de um processo de retomada da realidade vivida que usualmente se transforma na linha de uma crescente criatividade.

Palavras-chave: TEA, Imaginação, Teoria histórico - Cultural, Função Psicológico Superior, Educação Especial.

\section{IMAGINATION DEVELOPMENT WITH AUTISM SPECTRUM DISORDER (ASD) IN HISTORICAL PERSPECTIVE - CULTURAL}

\begin{abstract}
The development of higher psychological function imagination of children with Autism Spectrum Disorder (ASD) is described as very small and quirky. With concern the search for promising educational practices, this article made reference to the historical-cultural theory and aimed to highlight the particularity of the child's imagination development with ASD order to understand it. The literature has enabled us to understand that autistic children may have imaginative actions since it happens one detachment of instant-concrete situation, in which the meaning becomes subordinate perception that is typical of the imagination process. It is a lived reality recovery process that usually turns in line with a growing creativity.
\end{abstract}

Keywords: TEA, Imagination, History Theory - Cultural, Superior Psychological Function, Special Education. 


\section{INTRODUÇÃO}

O Transtorno do Espectro do Autismo (TEA) é classificado como um distúrbio global do desenvolvimento, no qual há um comprometimento em diversas áreas do comportamento e do psiquismo. Na descrição da Classificação Internacional de Doenças - CID 10 (Organização Mundial da Saúde, 1993), essa patologia é definida como um transtorno invasivo do desenvolvimento, identificado pelo surgimento antes da idade de 3 anos e "pelo tipo característico de funcionamento anormal em todas as três áreas de interação social, comunicação e comportamento restrito e repetitivo" (p. 247).

Também na discussão atual dos diferentes quadros abrangidos pelos Transtornos do Espectro do Autismo (TEA) é salientada a sintomatologia básica da tríade autística, referente à problemas na interação social, comunicação e padrão comportamental (Schwartzman \& Araújo, 2011).

Em relação ao brincar, foco do presente trabalho, a descrição da CID 10 indica que essa atividade encontra-se alterada pelas características gerais do transtorno:

A condição é também caracterizada por padrões de comportamento, interesses e atividades restritos, repetitivos e estereotipados. Isto toma a forma de uma tendência a impor rigidez e rotina a uma ampla série de aspectos do funcionamento diário; usualmente, isto se aplica tanto a atividades novas como a hábitos familiares e à padrões de brincadeiras. (ORGANIZAÇÃO MUNDIAL DA SAÚDE, 1993, p. 248).

Na mesma linha, o DSM-IV (American Psychiatric Association, 1995) indica que, nos casos de autismo, em geral os elementos imaginativos estão ausentes ou apresentam prejuízo acentuado. Além disso, as crianças tendem a não se envolver em rotinas simples da infância, ou o fazem fora de contexto e de um modo mecânico.

Estudos com sujeitos autistas tendem a reiterar a indicação de que eles não conseguem se relacionar com seus pares e fazer amigos, precisam de criatividade e iniciativa e apresentam habilidades sociais muito limitadas e, particularmente, fracassam no desenvolvimento da empatia dada as características do transtorno.

Nessa linha, costuma-se afirmar que as crianças autistas demonstram uma preferência por objetos e não por pessoas.

Tendo em vista as dificuldades de comunicação e interação dessas crianças, as relações que os outros estabelecem com ela podem mostrar-se comprometidas muitas vezes desde o nascimento, ou assim que se evidencia o transtorno.

Não se trata de culpabilizar pais e familiares, mas de considerar que os fracassos na interação se devem em boa parte ao modo como as pessoas próximas reagem à falta de respostas e de contato do autista, o que certamente afeta seu desenvolvimento, muitas vezes cristalizando o quadro já instalado.

Bosa (2002) discute a dificuldade que os outros têm para compreender a forma como os autistas comunicam suas necessidades e desejos, e argumenta que um olhar mais atento permite observar o grande esforço que esses sujeitos despendem para encontrar recursos que propiciem a compreensão do que estão expressando.

Ao tomarmos a análise de registros de filmagem que Bosa (2002) realizou em uma pesquisa com crianças autistas, foi possível verificar que a autora verificou que o olhar que dirigem para as pessoas, muitas vezes descrito como quase ausente, é na verdade mais frequente do que se imagina, particularmente nas situações em que a criança necessita do adulto. Entretanto, são olhares breves e quase imperceptíveis.

Essa característica e a baixa frequência podem ser interpretadas pelo adulto como uma incapacidade de entender "a função comunicativa do olhar" para compartilhar experiências com as pessoas. 
Bosa (2002) enfatiza ainda "que essa suposição parece trivial, mas faz muita diferença quando aplicada em um contexto de intervenção junto aos pais, pois, não olhar porque não compreende a extensão das propriedades comunicativas do afeto e do olhar é diferente de não querer olhar" (p. 36, grifo da autora).

Como as ações da criança são percebidas como movimento e manipulação sem sentido, a mãe e as pessoas próximas vão deixando de significá-las, o que pode interferir em seu desenvolvimento, sobretudo no se refere a aquisição da linguagem.

Assim sendo, o presente artigo tem como objetivo evidenciar a particularidade do desenvolvimento da imaginação da criança com transtorno do espectro autista visando compreender essa particularidade.

\section{METODOLOGIA}

Para o desenvolvimento do presente trabalho da revisão bibliográfica de caráter qualitativo que de acordo com Menga \& André (1986) enquadra-se na modalidade de reconhecimento da realidade de seus sujeitos, observação cuidadosa, estruturada e sistemática, garantindo um olhar rigoroso sobre o campo de pesquisa e a descrição cuidadosa dos elementos nele identificados pelo pesquisador. Conforme as autoras, a pesquisa qualitativa assume que o conhecimento não é algo acabado, mas uma construção que se faz e refaz constantemente e que possibilita novas respostas e indagações ao longo do processo de pesquisa.

\section{RESULTADOS E DISCUSSÃO}

O processo de desenvolvimento da atividade da criança abarca o desenvolvimento das funções psicológicas. Em pleno acordo Leontiev (2001), é possível o estabelecimento de uma regra no sentido do desenvolvimento psicológico da criança onde que o desenvolvimento dessas funções encontra-se dependente da atividade da criança, no caso, [...] qualquer função se desenvolve e é reestruturada dentro do processo que a realiza.

Contudo, esta afirmação do autor vale ser ressaltada no sentido de esclarecer que as funções psicológicas da criança não podem em hipótese alguma se resumir a um contexto de treinamento simplesmente mecânico no que tange à apropriação da linguagem, do pensamento, da memoria voluntária, do ato motor voluntário, da imaginação, entre outras funções psicológicas superiores.

Nesta direção, crava-se ai, uma condição irrevogável para o processo de desenvolvimento das funções psicológicas superiores, a de serem ao contrário de outras funções, direcionadas e ministradas em um contexto intencionado enquanto intenção para a realização da atividade. Referente a isso e para exemplificar, LEONTIEV (2001, p.78) coloca para o processo com a aprendizagem de uma língua estrangeira:

[...] quando a criança começa a estudar uma língua estrangeira, no começo não ouve a diferença entre fonemas semelhantes, que são novos para ela [...]. Além disso, é notável o fato de que para se tornar sensível a esta diferença não basta ouvir frequentemente falar a língua francesa, sem todavia tentar dominá-la. É isso que torna possível que alguém passe muitos anos entre pessoas que falam outra língua e, mesmo assim, permaneça surdo às nuanças de sua fonética.

Isso implica afirmar que quanto mais amplas, diversificadas, ricas e intencionais forem as experiências, apropriações e objetivações humanas, melhores e mais abundantes serão as condições para o desenvolvimento de suas funções psicológicas superiores.

Arce e Martins (2007), baseadas na reflexão Vigotskiana, postulam que os processos neuropsicológicos, enquanto se desenvolvem e se transformam, constituem-se num sistema inteiramente novo os quais, de processos naturais e elementares (percepção, atenção e memória 
involuntárias, linguagem emocional), transformam-se em processos superiores e complexos, decorrente das influências culturais e de condições concretas de vida, como resultado de interação ativa com o ambiente.

Assim, as funções psicológicas superiores têm origem sócio - histórica, porém surgem de estruturas orgânicas, biológicas as chamadas funções psicológicas elementares ou primárias que tem na sua essência as características biológicas, e a partir das apropriações culturais damos saltos qualitativos no desenvolvimento numa direção de formação de estruturas complexas.

Dessa forma, não podemos considerar apenas o desenvolvimento maturacional e biológico do indivíduo como fator preponderante para o desenvolvimento da função psicológica superior imaginação, menos ainda, colocá-la como condição para determinar que uma criança é mais imaginativa que um adulto. Para tanto temos:

O processo principal que caracteriza o desenvolvimento psíquico da criança é um processo especifico de apropriação das aquisições do desenvolvimento das gerações humanas precedentes; estes conhecimentos adquiridos, diferentemente dos do desenvolvimento filogenético dos animais, não se fixam morfologicamente e não se transmitem por hereditariedade. (LEONTIEV,1978, p. 323).

As funções psicológicas superiores são exclusivamente humanas, se constituem e se caracterizam por uma relação mediada, ou seja, uma relação de caráter não imediato entre os sujeitos e os estímulos do ambiente. O traço distintivo de uma operação psicológica superior relaciona-se com o signo, que é um meio artificial criado pelos homens como forma de controle da própria conduta.

Vigotskii (1998) postula que a imaginação tem relação direta com a riqueza de experiências que o indivíduo acumula ao longo de sua vida; condição fundamental e necessária na construção dessa importante função psicológica.

O autor também afirma que quanto mais ricas forem as experiências humanas, melhores e mais abundantes serão as condições para o desenvolvimento da imaginação, além de coloca-la sob dois aspectos: o de reprodução e o de reelaboração/ criação.

Ao discutir sobre o aspecto de reprodução, Vigotskii $(1998$, p.7) afirma que este está estreitamente vinculado com a memória e que sua essência se dá quando o homem reproduz ou repete normas e condutas criadas e elaboradas pelo homem. Esta particularidade da imaginação, portanto, nos remete a pensar no que não tem nada novo como criação, portanto ao ouvirmos uma criança repetir o que ouviu não significa que ela está imaginando, muito pelo contrário, está simplesmente reproduzindo.

Já em relação ao segundo aspecto, este se dá no sentido de permitir que a reprodução de ações, impressões, resulte em novas ações e impressões. Neste contexto, Vigotskii $(1998$, p. 9) defende que a imaginação ou fantasia enquanto atividade criadora do cérebro humano, e este como órgão capaz de conservar, reproduzir e criar novos elementos a partir disso, recebe um sentido bastante diferente ao qual correspondem cientificamente.

"A criança emprega sua imaginação no que a impressiona fortemente", portanto terminantemente uma criança em idade pré-escolar, apesar de verbalizar situações que aparentemente demonstram indícios de imaginação, isto está equivocado.

Para que o desenvolvimento da imaginação aconteça depende-se das apropriações e objetivações do que foi construído pela humanidade ao longo da história logo não poderemos ais afirmar que uma criança imagina mais que um adulto, pois não se apropriou da cultura mais que ele, pelo contrário. $O$ fato da imaginação de uma criança não é senão inferior à imaginação de um adulto, já que a criança combina imagens de maneiras muito menos diversas, mas não menos importante. 
Nesta direção, defende Mukina $(1995$, p.294) que a imaginação desempenha na vida da criança um papel mais importante que na vida do adulto, por manifestar-se com mais frequência e se desligar da vida do adulto para que a criança saiba distinguir o que foi imaginado e o que é real, e continua, "[...] a imaginação em constante funcionamento amplia o conhecimento que a criança tem do mundo circundante e lhe permite extrapolar os limites de sua pobre experiência pessoal".

Neste sentido, constatamos que para que seja possível imaginar mais, podendo assim criar coisas novas, é preciso ampliar as relações sociais, além de se apropriar do que a humanidade construiu.

\section{CONCLUSÃO}

As crianças autistas podem apresentar ações imaginativas, desde que aconteça um desprendimento da situação imediato-concreta, pela qual a significação passa a subordinar a percepção (Vigotski, 1984). Essa subordinação é típica do brincar e se faz presente particularmente no jogo de papéis, em que há recriação de situações do cotidiano, envolvendo ações sobre objetos e relações entre pessoas (Elkonin, 1984). Trata-se de um processo de retomada da realidade vivida que usualmente se transforma na linha de uma crescente criatividade.

Segundo Leontiev (1967) apud Edit e Duarte (2007) " [...] a criança se encontra com um mundo criado e transformado pela atividade humana das gerações precedentes. Ela não pode simplesmente "estar" neste mundo, precisa viver e atuar sobre o mundo, usando instrumentos, o idioma e a lógica já elaborados pela sociedade" e, nesse sentido, podemos compreender que a criança não nasce preparada para atuar na sociedade, e realizar tarefas que garantam sua sobrevivência. Esta preparação ocorre em decorrência da apropriação das relações sociais e da cultura humana, mediadas pelo outro. O processo de apropriação e objetivação da cultura viabilizará o desenvolvimento da imaginação voluntária.

A apropriação emerge a partir da busca e das condições objetivas que o sujeito encontra para agir em prol do atendimento das suas necessidades de desenvolvimento, assim, é na apropriação de objetos naturais e culturais (materiais e simbólicos) que o indivíduo dispõe das possibilidades objetivas de desenvolvimento das mais variadas funções psicológicas superiores, dentre elas a linguagem, o pensamento, sentimentos, dentre outras e, nesse movimento, construir habilidades e capacidades essenciais para viver em sociedade e se humanizar a partir dela.

Capacidades humanas como imaginação, criatividade, segurança, autonomia, dentre outras, se formam e se desenvolvem a partir de processos educativos e o professor, e a escola, obviamente, tornam-se imprescindíveis na vida dos seres humanos, tendo em consideração que é na objetivação dos objetos materiais e simbólicos da cultura que cada indivíduo se tornará humano.

Cabe colocar que para o desenvolvimento das funções psicológicas (FPS) superiores e o brincar torna-se necessário um trabalho mediado por um indivíduo culturalmente mais desenvolvido e, no ambiente escolar, este indivíduo é o professor, o qual, na relação professor-aluno é o que possibilita o avanço dos alunos. Podemos afirmar, sem medo de errar, que o professor é o sujeito que contribui para a formação dos alunos na direção da sua humanização, criando condições de apropriação da cultura no interior da escola.

\section{REFERÊNCIAS}

BAGAROLLO, M. F. A Ressignificação do Brincar das Crianças Autistas. Dissertação de Mestrado, Universidade Metodista de Piracicaba - UNIMEP, Piracicaba, São Paulo, 2005.

BOSA, C. Autismo: Atuais Interpretações para Antigas Observações. Em C. R. Baptista \& C. Bosa (Orgs.), Autismo e Educação: Reflexões e Propostas de Intervenção (pp. 21-39). Porto Alegre: Artmed, 2002. 
ELKONIN, D. B. (1984). Psicología del juego. Havana: Pueblo y Educación.

LEONTIEV, A.N. Os princípios psicológicos da brincadeira pré-escolar. In: VIGOTSKI, L.S.; LURIA, A.R.; LEONTIEV, A.N. Linguagem, desenvolvimento e aprendizagem. 6. ed. São Paulo: EDUSP, 1998b. p. 119-142.

LEONTIEV, A.N. O desenvolvimento do psiquismo. Lisboa: Livros Horizonte, 1978.

LEONTIEV, A.N. Uma contribuição à teoria do desenvolvimento da psique infantil. In: VIGOTSKII, L.S., LURIA, A.R. \& LEONTIEV, A.N. Linguagem, desenvolvimento e aprendizagem. 9 ed. São Paulo: Ícone, 2001.

MARINO FILHO, A. Implicações Psicopedagógicas da Brincadeira: Aprender a fazer, aprender a ser. In: Psicologia \& Educação: Perspectivas críticas para a ação psicopedagógica. 1. ed.Birigui, SP: Boreal Editora, 2012. p. 136-163.

MENGA, L.; ANDRE, M. E. D. A. Pesquisa em educação: abordagens qualitativas. São Paulo: EPU, 1986.

MUKINA, V. Psicologia da idade pré-escolar. São Paulo: Martins Fontes, 1995.

ORGANIZAÇÃO MUNDIAL DA SAÚDE. Classificação de Transtornos Mentais e do Comportamento da CID - 10: Descrições Clínicas e Diretrizes Diagnósticas. Porto Alegre: Artes Médicas, 1993.

SCHWARTZMAN, J. S., ARAÚJO, C. A. (Orgs.). Transtornos do espectro do autismo. São Paulo: Memnon, 2011.

VIGOTSKI, L. S. A Formação Social da Mente. São Paulo: Martins Fontes, 1984. 